\title{
A ESTRATÉGIA DE SEGMENTAÇÃO DE MERCADO COMO VANTAGEM COMPETITIVA: UM ESTUDO EXPLORATÓRIO NO SETOR DE TURISMO “SINGLE” A PARTIR DA CIDADE DE SÃO PAULO
}

\section{RESUMO}

\author{
1 Roberto Bazanini \\ 2 Ademir Antonio Ferreira \\ 3 José Ricardo Ramos Féris \\ 4 Fernando Araújo Ravagnani
}

Este artigo é resultado de uma pesquisa realizada com quatro empresas do setor de turismo (agências e operadoras) da cidade de São Paulo, que realizam programas de viagens especiais para o segmento de pessoas que viajam sozinhas. Por meio de pesquisa exploratória de natureza qualitativa, o objetivo da pesquisa está em investigar se as empresas que incluíram no seu portfólio de negócios um programa específico para o turismo "single" alcançaram a lealdade e fidelidade desse grupo de clientes e obtiveram vantagem competitiva sobre os concorrentes que não adotaram esse tipo de segmentação. Buscou-se explorar nas entrevistas e levantamento de dados junto às empresas, o perfil do turista "single", a sua motivação e expectativas, assim como a estratégia adotada e as atividades desenvolvidas pela empresa para atendê-los. Os resultados da pesquisa apontam que as empresas que optaram por segmentar seu mercado para o turismo "single" geralmente o fizeram por perceber a existência de um nicho latente a ser explorado, mas somente a empresa que adota a concentração de mercado nesse segmento obtém vantagem competitiva.

Palavras-chave: turismo single, segmentação de mercado, vantagem competitiva.

\section{MARKET SEGMENTATION STRATEGY AS A COMPETITIVE ADVANTAGE: AN EXPLORATION STUDY ON "SINGLE" TOURISM SECTOR IN SÃO PAULO CITY}

\begin{abstract}
This article is the result of a survey conducted with four companies of the tourism sector ( agencies and operators ) from São Paulo, who perform special travel programs for the segment of people traveling alone. According exploratory and qualitative nature, the main focus of the research was to assess the perception of the leaders of these companies , there competitive advantage by specializing in the needs and desires of a particular market segment. We sought to explore in the interviews and survey data from the companies, the tourist profile "single", their motivation and expectations, as well as the strategy and the activities conducted by the company to serve them. It found that companies who have chosen to target your market for tourism "single" usually did so by realizing the existence of a latent niche to be exploited, but only the company that adopts market concentration in this segment obtains competitive advantage.
\end{abstract}

Key words: tourism single, market segmentation, competitive advantage.

\footnotetext{
${ }^{1}$ Doutor em Comunicação e Semiótica pela Pontifícia Universidade Católica, São Paulo - PUC, Brasil. Professor titular do Mestrado em Administração da Universidade Paulista - UNIP, Brasil.

E-mail: roberto.bazanini@terra.com.br

2 Doutor em Administração pela Universidade de São Paulo - USP, Brasil. Professor titular da Universidade Paulista - UNIP, Brasil.

E-mail: adeafer@gmail.com

${ }^{3}$ Mestre em Administração pela Universidade Paulista - UNIP, Brasil.

E-mail: r_feris@uol.com.br

${ }^{4}$ Mestrando em Administração Universidade Paulista - UNIP, Brasil.

Engenheiro Elétrico pelo Centro Universitário da Fundação Educacional de Barretos - UNIFEB

E-mail: fernando@ sikora-brazil.com
} 
A Estratégia de Segmentação de Mercado Como Vantagem Competitiva: Um Estudo Exploratório no Setor de Turismo "Single" A Partir da Cidade de São Paulo

\section{INTRODUÇÃO}

O presente artigo busca discutir o mercado turístico por meio da segmentação do mercado associado às visões da economia e do marketing, tendo por referência teóricos como Bowen (1998, 1997), Harrys e Watkins (1998), Hu (1996) Cooper (2001), Stokes (2006), Oliveira, Campomar e Luis (2008), autores esses, que abordam predominantemente as estratégias de marketing em nossa contemporaneidade em seus diferentes aspectos mercadológicos.
O turismo detém, hoje, grande parte do PIB de muitos países, que têm melhorado suas condições econômicas e socioeconômicas, em decorrência do avanço que o setor tem proporcionado. Em muitos desses países e em regiões privilegiadas pela natureza, o turismo é a principal, senão a única, atividade econômica explorada. Para se ter uma ideia do crescimento do turismo nos cinco continentes, entre 2005 e 2014, a tabela 1 se torna bastante instrutiva.

Tabela 1. Demanda Turística - por região do mundo

\begin{tabular}{|l|c|c|c|c|c|c|c|c|c|c|}
\hline Ano & 2005 & 2006 & 2007 & 2008 & 2009 & 2010 & 2011 & 2012 & 2013 & 2014 \\
\hline $\begin{array}{l}\text { Mundo (total de } \\
\text { turistas/milhões) }\end{array}$ & 803 & 847 & 904 & 922 & 882 & 940 & 982 & 1035 & 1087 & 1138 \\
\hline Europa & $54,6 \%$ & $\begin{array}{c}54,5 \\
\%\end{array}$ & $\begin{array}{c}53,9 \\
\%\end{array}$ & $\begin{array}{c}52,9 \\
\%\end{array}$ & $\begin{array}{c}50,6 \\
\%\end{array}$ & $\begin{array}{c}51,2 \\
\%\end{array}$ & $51,3 \%$ & $\begin{array}{c}51,7 \\
\%\end{array}$ & $\begin{array}{c}51,8 \\
\%\end{array}$ & $51,7 \%$ \\
\hline Ásia e Pacífico & $19,3 \%$ & $\begin{array}{c}19,7 \\
\%\end{array}$ & $\begin{array}{c}20,1 \\
\%\end{array}$ & $\begin{array}{c}20,0 \\
\%\end{array}$ & $\begin{array}{c}21,7 \\
\%\end{array}$ & $\begin{array}{c}22,0 \\
\%\end{array}$ & $22,1 \%$ & $\begin{array}{c}22,5 \\
\%\end{array}$ & $\begin{array}{c}22,8 \\
\%\end{array}$ & $23,1 \%$ \\
\hline $\begin{array}{l}\text { América Central e } \\
\text { Caribe }\end{array}$ & $3,1 \%$ & $\begin{array}{c}3,13 \\
\%\end{array}$ & $3,0 \%$ & $3,1 \%$ & $2,9 \%$ & $3,1 \%$ & $2,9 \%$ & $2,8 \%$ & $2,8 \%$ & $2,8 \%$ \\
\hline América do Norte & $11,2 \%$ & $\begin{array}{c}10,7 \\
\%\end{array}$ & $\begin{array}{c}10,5 \\
\%\end{array}$ & $\begin{array}{c}10,6 \\
\%\end{array}$ & $\begin{array}{c}10,4 \\
\%\end{array}$ & $\begin{array}{c}10,3 \\
\%\end{array}$ & $10,3 \%$ & $\begin{array}{c}10,2 \\
\%\end{array}$ & $\begin{array}{c}10,1 \\
\%\end{array}$ & $10,5 \%$ \\
\hline América do Sul & $2,3 \%$ & $2,2 \%$ & $2,2 \%$ & $2,3 \%$ & $2,6 \%$ & $2,6 \%$ & $2,6 \%$ & $2,6 \%$ & $2,5 \%$ & $2,5 \%$ \\
\hline Africa & $4,7 \%$ & $4,9 \%$ & $5,0 \%$ & $5,1 \%$ & $5,3 \%$ & $5,1 \%$ & $5,1 \%$ & $5,1 \%$ & $5,1 \%$ & $4,9 \%$ \\
\hline Oriente Médio & $4,8 \%$ & $4,8 \%$ & $5,2 \%$ & $6,0 \%$ & $6,5 \%$ & $5,7 \%$ & $5,6 \%$ & $5,1 \%$ & $4,7 \%$ & $4,4 \%$ \\
\hline
\end{tabular}

Fonte: Organização Mundial do Turismo 2014

Observa-se na demanda do turismo na Europa indices percentuais significativos em relação aos demais continentes, mas, de modo geral, as demandas turísticas se mantiveram constantes nessas duas décadas.

No Brasil, a demanda turistica cresceu de forma mais lenta, conforme tabela 2 .

Tabela 2. Demanda Turística - Participação do Brasil no Mundo

\begin{tabular}{|l|l|l|l|l|l|l|l|}
\hline Ano & $\begin{array}{l}\text { Mundo } \\
\text { (Milhões) }\end{array}$ & $\begin{array}{l}\text { América do Sul } \\
\text { (Milhões) }\end{array}$ & $\begin{array}{l}\text { Brasil } \\
\text { (Milhões) }\end{array}$ & $\begin{array}{l}\text { América do Sul } \\
\text { no mundo }\end{array}$ & $\begin{array}{l}\text { Brasil na } \\
\text { América do } \\
\text { Sul }\end{array}$ & $\begin{array}{l}\text { Brasil } \\
\text { mundo }\end{array}$ \\
\hline 2005 & 803 & 18,3 & 5,4 & $2,3 \%$ & $29,3 \%$ & $0,7 \%$ \\
\hline 2006 & 847 & 18,7 & 5 & $2,2 \%$ & $26,7 \%$ & $0,6 \%$ \\
\hline 2007 & 904 & 20,0 & 5 & $2,2 \%$ & $25,0 \%$ & $0,6 \%$ \\
\hline 2008 & 922 & 20,8 & 5,1 & $2,3 \%$ & $24,3 \%$ & $0,5 \%$ \\
\hline 2009 & 882 & 22,9 & 4,8 & $2,3 \%$ & $23,4 \%$ & $0,5 \%$ \\
\hline 2010 & 940 & 24,4 & 5,2 & $2,5 \%$ & $22,0 \%$ & $0,5 \%$ \\
\hline 2011 & 982 & 25,8 & 5,4 & $2,6 \%$ & $20,9 \%$ & $0,5 \%$ \\
\hline 2012 & 1035 & 26,9 & 5,7 & $2,6 \%$ & $20,0 \%$ & $0,5 \%$ \\
\hline 2013 & 1087 & 27,4 & 6 & $2,5 \%$ & $22,0 \%$ & $0,5 \%$ \\
\hline 2014 & 1138 & 29 & 6 & $2,5 \%$ & $22 \%$ & $0,5 \%$ \\
\hline
\end{tabular}

Fonte: Anuário 2015- Base 2014.

Observa-se que embora o crescimento tenha se tornado contínuo na América do Sul, o Brasil não acompanhou esse crescimento se comparado aos demais paises do continente.
Neste estudo serão consideradas as atividades turísticas que envolvem serviços de alojamento; serviços de alimentação; transportes ferroviário e metroviário; transporte rodoviário; transporte aéreo; transporte aquaviário e serviços 
auxiliares de transporte; atividades de agências e organizadores de viagens; aluguel de bens móveis e atividades recreativas, culturais e desportivas. (MTUR, 2012a)

Isso pode significar e indicar que a atividade turística, na perspectiva de lazer, é importante para contribuir na melhoria da qualidade de vida da população e no aspecto econômico, contribui para o melhor desempenho da economia local e regional.

Conforme evidenciado por Hoeller (2002), o redirecionamento dos processos industriais no mundo inteiro, a busca por produtividade e os avanços na tecnologia de produção passaram a ter melhor qualidade, menor custo e consequentemente provocaram a necessidade de uma utilização racional do tempo livre. Deve-se acrescentar às evidências desses autores, as conquistas da classe trabalhadora dos países desenvolvidos, no âmbito dos benefícios sociais e aumento da renda discricionária.

Nesse contexto, o Brasil, com todas as suas riquezas naturais e também culturais, pode explorar a atividade turística como potencialidade econômica na geração de riqueza e fomentar investimentos de empreendedores.

Desde o final do século passado tem-se notado um avanço significativo nos investimentos do setor. Em reportagem publicada na revista Viagem e Turismo, Angotti (2002, p. 46), ressalta que outro fator importante é a própria implantação de novos complexos turísticos principalmente no Nordeste brasileiro. Os maiores investimentos têm sido realizados por redes hoteleiras espanholas e portuguesas (Sol Meliá, Iberostar, Pestana, Vila Galé), mediante a construção de resorts no litoral nordestino e hotéis de muitas estrelas nas capitais do país.

A profissionalização da atividade turística também tem favorecido esse aquecimento. Em uma década surgiram, no Brasil, centenas de cursos de nível técnico e bacharelado, para formação em turismo e/ou hotelaria. Se quisermos entrar na lista dos maiores destinos turísticos do mundo, temos que nos profissionalizar, buscar qualificações, estar aptos para exercer funções e suportar desafios.

Deve ser considerado um fator importante, se não o mais importante, a cultura do turismo. As pessoas têm se conscientizado da importância de rever conceitos sobre qualidade de vida. Isso favorece a procura pelo turismo, por novos destinos.

Neste estudo estará sendo analisado o mercado formado por pessoas que viajam sós, um segmento de mercado turístico, considerado atraente e em acentuado crescimento na demanda. (MORAES, 2002).

Por meio de pesquisa exploratória, de natureza qualitativa o objetivo da pesquisa está em investigar se as empresas que incluíram no seu portfólio de negócios um programa específico para o turismo "single" conseguiram a lealdade e fidelidade desse grupo de clientes e obtiveram vantagem competitiva sobre os concorrentes que não adotaram esse tipo de segmentação.

O problema da pesquisa está em responder à questão: como as estratégias de segmentação de mercado foram empregadas pelas agências de turismo que alcançaram vantagem competitiva em relação à concorrência?

Optou-se por estudar o turismo "single" a partir da cidade de São Paulo, em virtude da facilidade de acesso às informações e de se situar como um polo gerador mais importante de todas as atividades econômicas do país. Deve ser ressaltado também que, numa abordagem inicial do problema, foi observado que é um segmento considerado pelas operadoras de viagens e agências de viagens locais como um novo nicho de mercado.

\section{TURISMO E SEGMENTAÇÃO DE MERCADO}

Dentre os inúmeros estudos publicados sobre a segmentação do mercado nas atividades turísticas, podem-se destacar: Cortés-Jiménez (2008), Elliot \&Choi (2011), Dede (2013). Cortés-Jiménez (2008), descreve a importância do turismo no continente europeu e a necessidade de se ampliar a segmentação dos mercados; Elliot \&Choi (2011) privilegiam os aspectos motivacionais do turismo nas terapias ocupacionais; Dede (2013); enfatiza as atividades turísticas como fator de desenvolvido econômico e a respectiva competitividade das agências promotoras.

A palavra turismo deriva de tour (palavra francesa), que é originária do latim tornare e do grego tornus, e cujo significado é giro ou círculo. Por sua vez, a OMT- Organização Mundial de Turismo (1978) conceitua turismo como: "o deslocamento voluntário e temporário do homem fora de sua residência habitual, por uma razão diferente do que a de exercer uma atividade remunerada".

Mais recentemente a OMT acrescentou a esse conceito, as atividades realizadas pelas pessoas durante suas viagens e estadas em lugares distintos do seu entorno habitual, por um período consecutivo, inferior a um ano, por lazer, negócios e outros. (OMT, 2003)

Assim, turismo representa o ato de partir e posteriormente regressar ao ponto inicial, sendo que o realizador desse giro é denominado turista.

$\mathrm{O}$ aspecto econômico da atividade focaliza as transações realizadas pelo turista e o aspecto social enfatiza a questão principal que é o deslocamento dos indivíduos, o qual deve ser voluntário e temporário, pois o indivíduo tem que ter motivação para se deslocar e deve ter um tempo pré-estabelecido. Esse tempo tem que ser superior a vinte e quatro horas, ou seja, tem que efetuar pernoite. Deve ser observado também que um viajante a negócios, geralmente, efetua gastos significativos no local visitado. Por isso é considerado turista.

Segundo Ignarra (2001, p. 25) o turismo pode ser entendido como "um complexo de atividades $e$ 
serviços relacionados aos deslocamentos, transportes, alojamentos, alimentação, circulação de produtos típicos, atividades relacionadas aos movimentos culturais, visitas, laser $e$ entretenimento". Esse conceito inclui outro tópico importante: atividades que compõem o turismo.

$\mathrm{O}$ fenômeno turístico não poderia acontecer se não houvesse outros serviços para auxiliá-lo. Um exemplo disso é a hotelaria. Sem os meios de hospedagem, não haveria como os turistas se alojarem nos lugares visitados. Outro exemplo, ainda mais prático, são os meios de transporte, já que, sem eles, não haveria como os indivíduos se deslocarem até os centros receptores escolhidos.

Segundo Beni (1998, p. 37), "o turismo pode identificar-se em três tendências para a sua definição: a econômica, a técnica e a holística". Então, entende-se que se deve formar um conceito com essas três tendências, para que haja um entendimento comum entre todos os que estudam o turismo. $\mathrm{O}$ autor situa o turismo como uma atividade socioeconômica, que envolve deslocamentos que têm os mais diversos motivos, na qual o turista permanece por um período superior a vinte e quatro horas e realiza gastos no local visitado, movimentando uma grande cadeia produtiva, adquirindo e aprendendo os costumes e tradições da população local.

Os conceitos relatados por Beni (1998), Moraes (2002), Ignarra (2001) e a OMT, mostram a complexidade da atividade, uma vez que a relacionam com motivações, viagens, diferentes culturas e ainda vários segmentos de turistas. Com isso, o turismo deve ser estudado como um todo e não apenas em partes.

Nesse sentido, Beni (1998) sugere que a melhor maneira de estudar o mercado turístico é por meio de sua segmentação, a qual permite decompor a população em grupos de igual gênero e natureza, acompanhando um programa de marketing próprio e focalizado nas características do segmento. Essa segmentação possibilita a adequação dos "pacotes turísticos" em termos de destinos geográficos potenciais, do tipo de transporte, da acomodação, dos passeios, visitas e locais atrativos para esse público. Efetivamente, informações das características demográficas dessa população se tornam essenciais para a formulação de programas turísticos atraentes e dirigidos para esse público-alvo: faixa etária, nível econômico, sexo, domicílio, bases culturais, amizades, relações pessoais, instrução, classe de renda, ocupação, mobilidade social, etc..

\section{Bases para a segmentação de mercado}

O fundamento da segmentação de mercado baseia-se na ideia de que um produto comum não pode satisfazer necessidades e desejos de todos os consumidores, uma vez que os consumidores são muitos, dispersos em diversas regiões; têm hábitos de compra variados, gostos diferenciados e variam em suas necessidades, desejos e preferências. Assim sendo, não se pode tratar a todos da mesma forma, bem como não se pode tratar todos de forma diferente. $\mathrm{O}$ que se pode fazer é tentar reunir grupos de pessoas com características, preferências e gostos semelhantes, e tratá-los como se fossem iguais.

Como se percebe, o centro de toda a discussão é que existem diferenças entre os consumidores. Diferenças essas que devem ser consideradas no processo decisório da empresa. Daí, a importância da segmentação de mercado como instrumento estratégico, que começa a ganhar força a partir da publicação do artigo de Wendell Smith (1956), no Journal of Marketing, EUA, intitulado: "Diferenciação do Produto e Segmentação de Mercado como Alternativas de Estratégia Mercadológica". Nesse clássico do Marketing, Smith vê a segmentação como condição indispensável para o crescimento da empresa. Ressalta ainda, que a segmentação é baseada em desdobramentos do lado da oferta de mercado, e representa um ajuste mais racional e preciso do produto, e do esforço mercadológico, para $\mathrm{o}$ pronto atendimento às exigências do consumidor.

McCarthy (1982, p.173), defendeu a adoção da segmentação para maior sucesso no atingimento dos objetivos da empresa, incluindo-a nas considerações estratégicas do marketing mix. Kotler (1992, p. 177), reconhece que a segmentação de mercado está no cerne da estratégia de marketing. Segundo o mesmo autor, na segmentação de mercado a ideia mais recente para orientar a estratégia, começa com a distinção de interesses ou de necessidades de clientes.

Lage e Milone (2001, p. 103) assinalam que: "a segmentação de mercado no turismo não é uma noção acadêmica, mas uma estratégia que busca encontrar, por meio de recursos de marketing, maior otimização do setor, seja pelo lado das empresas turísticas na tentativa de maximizar seus lucros, seja pelo lado dos turistas na tentativa de maximizar sua satisfação".

O mercado turístico é composto por compradores que diferem entre si em um ou mais aspectos, como por exemplo, em termos de desejos, poder de compra, localização geográfica, atitudes, etc.. A segmentação do mercado turístico permite o reconhecimento dos principais destinos geográficos, tipo de transporte utilizado, a composição demográfica do fluxo turístico, etc.

Com relação à importância da ação de segmentação, Lage (1992, p. 105), afirma que:

"a estratégia de segmentação de mercado reconhece que poucas zonas de destinação turística são possíveis $e$ desejáveis em escala universal. Consequentemente, em lugar de dissipar os recursos de promoção com a intenção de contemplar todos os consumidores em potencial, a melhor estratégia de mercado é 
assinalar quais são os segmentos do mercado turístico total que se deseja atingir. $e$ dirigir os esforços promocionais especificamente aos desejos e necessidades desse grupo".

Os critérios para a segmentação do mercado de turismo acompanham aqueles adotados tradicionalmente para a análise de um mercado de bens de consumo. Robert McIntosh, citado por Lage (1992, p. 103) defende a segmentação dos mercados turísticos de acordo com critérios demográficos, geográficos, psicográficos, econômicos e sociais. Evidentemente, as variáveis que irão compor a configuração de cada critério serão específicas e inseridas na previsível matriz produto-mercado. Segundo a autora, o critério geográfico, em termos da procura por destinos turísticos inclui:

- curta e longa distância

- local, regional, continental e internacional

- áreas urbanas e rurais

- clima quente ou estações de inverno

- pequenas e médias cidades grandes metrópoles

Por outro lado, os pacotes turísticos oferecem opções para praia, montanha, verão inverno, marítimo, fluvial, urbano e rural.

Levando-se em consideração as variáveis demográficas, também se pode segmentar o mercado tanto a partir da oferta, quanto da demanda. Numa adaptação da proposta de Lage (1992), apresentamos as principais variáveis demográficas que podem servir como indicadores úteis para a segmentação.

- idade: infantil, juvenil, terceira idade;

- $\quad$ sexo ou opção sexual: masculino, feminino, turismo GLS;

- tamanho da família: individual, casais, turismo "single", grupos familiares;

- ciclo de vida da família: jovem: solteiro, casado (sem filhos, com filhos abaixo e acima de 6 anos; meia idade: casado

(com ou sem filhos), idoso, solteiro;

- renda: familiar ou individual;

- ocupação: empresário, profissional liberal, empregado, autônomo, aposentado;

- nível educacional

- religião

- $\quad$ origem étnica.

Do ponto de vista comportamental, que envolve os critérios psicográficos, econômicos e sociais, as variáveis selecionadas compreendem:

- classe social

- $\quad$ estilo de vida

- ocasiões especiais para viagem

- benefícios procurados em termos de custo e qualidade do serviço

- frequência e habitualidade do cliente

- lealdade ao roteiro e a agência

- grau de consciência do cliente sobre o produto oferecido

Entretanto, Beni (1998, p. 68) considera que:

"o motivo da viagem é o principal meio disponível para se segmentar o mercado”. Considerando-se, então, esse princípio, os principais segmentos de fluxo de turistas, se encontram no: turismo de lazer, de negócios, de compras, esportivo, ecológico, rural, aventura, religioso, cultural, científico, gastronômico, de eventos e de saúde. No propósito deste trabalho, todos esses motivos podem estar presentes, mas a contextualização do segmento está, primariamente, no comportamento de um grupo de pessoas que viajam sozinhas.

\section{O segmento "single"}

$\mathrm{Na}$ Língua Portuguesa as palavras: só, solitário e solidão, têm significados similares. Esses termos estão assim definidos no Dicionário da Língua Portuguesa (FERREIRA 2005):

- Solidão s.f. estado do que se encontra ou vive só, isolamento.

- Solitário adj. desacompanhado, isolado, que decorre em solidão, que gosta de estar só, que se sente impelido à solidão.

- Só adj. desacompanhado, solitário, que é só um, único, afastado da convivência, isolado.

- Só $a d v$. apenas, somente, unicamente.

- Só s.f. aquele que vive sem companhia.

Embora utilizados de forma semelhante e muitas vezes como sinônimos, esses vocábulos são colocados, geralmente, num contexto negativo. Sempre que se refere ao estado de solidão (solitário), há uma aura de tristeza, infelicidade, mesmo que o significado da palavra não seja esse. Entretanto, quando se diz que alguém está só, não se tem essa mesma sensação, por isso, optou-se pelo termo só, que é o mais próximo do sentido que se busca para compreender esse segmento do mercado turístico.

Portanto, esta definição não inclui apenas as pessoas que ao estarem sozinhas sentem-se abandonadas socialmente ou incapazes de se relacionar com os demais, mas também aquelas que se sentem bem sozinhas e gostam da companhia de outras pessoas. Entretanto, em muitas situações, a cidade, o trabalho, a família, os preconceitos, as formas de convivência social, entre outros fatores, impedem que esses relacionamentos sociais ocorram constantemente.

Existem várias categorias de "singles":

- o solteiro que mora só e pode ou não se sentir solitário;

- o solteiro que mora com os pais ou amigos e pode ou não se sentir solitário;

- o divorciado que está só novamente e também pode ou não se sentir solitário

- o viúvo que também pode ou não sentirse solitário.

- os homossexuais que, muitas vezes, por preconceito ou por não assumirem sua 
condição, tornam-se indivíduos solitários;

- a pessoa casada que, mesmo com outras pessoas em casa, sente-se solitária;

- a pessoa aposentada que perdeu o seu convívio social no local de trabalho ou que, ao ficar em casa, está só, pois os outros membros da família estão trabalhando ou estudando.

Como o turismo é globalizado e usualmente o inglês é o idioma internacional dos mercados e negócios, a expressão "single" é aceita e reconhecida universalmente para identificar o grupo de pessoas que viajam sozinhas a lazer e que compõem um expressivo segmento de mercado. A palavra "single", em inglês, pode significar só, solteiro, único e pessoa avulsa, entre outras conotações semânticas. Neste estudo, a palavra "single" está recebendo uma conotação de "pessoas que estão só", por opção ou não.

\section{Estratégia competitiva}

Acentuadamente, desde a década de 1980, o emprego do tema "estratégias" tem se evidenciado nos estudos organizacionais, evoluindo de uma visão puramente estática para uma visão mais dinâmica nos diversos setores da atividade econômica. Porter (1986) mostra que a vantagem competitiva surge na medida em que a empresa explora as diferenças, atendendo de forma superior seu segmento-alvo em relação aos concorrentes por segmento.

Hamel \& Prahalad (1995, p. 251), mostram a importância de uma competência essencial, uma vez que esta é a forma mais básica, uma fonte de vantagem competitiva, pois é competitivamente única, e contribui para o valor percebido pelo cliente, ou para o custo. Entretanto, ressaltam ainda que, embora todas as competências essenciais sejam fontes de vantagem comparativa, nem todas as vantagens comparativas são competências essenciais. Comentam que da mesma forma, toda competência essencial provavelmente seja um fator crítico de sucesso, mas nem todo fator crítico será uma competência essencial.

Seguindo a mesma linha de raciocínio, Porter (1999, p. 83), corrobora a questão da competitividade, mostrando que a revolução da informação vem afetando a competição de maneira vital. A mudança na estrutura setorial, e a alteração nas regras de competição, geram vantagem competitiva ao proporcionar às empresas novos modos de superar o desempenho dos rivais, disseminando negócios inteiramente novos, em geral a partir das atuais operações da empresa.

A definição de uma estratégia pode contribuir para que a empresa seja capaz de planejar seus negócios atuais e futuros. Essa focalização dos negócios leva em consideração o ambiente em que a empresa está inserida e sua disponibilidade e capacidade de alavancar recursos para investir, definindo um caminho, e alternativas a esse caminho, para que as decisões sejam tomadas.

Zaccarelli (2000, p. 92), mostra que a vantagem competitiva dependerá, cada vez mais, da inteligência no processo criativo de comunicação e da capacidade de manter a fidelidade do consumidor. Ressalta, ainda, que a primeira mudança é a passagem da atração pelo produto da empresa e pelo seu diferencial para a atração pela relação com o segmento. Cada vez mais se levará em conta a forma como a empresa estabelece sua relação com os clientes, quer se trate de consumidores finais quer de outras empresas.

$\mathrm{O}$ autor ressalta que a maior parte das empresas do setor de turismo se concentra na tecnologia e nos processos, e dedica pouca atenção ao papel da comunicação. Suponhamos, por exemplo, que uma empresa monte um centro de atendimento por telefone, para responder às dúvidas e queixas de seus clientes, com a melhor tecnologia disponível. Isso significa, por exemplo, que aparecerá na tela do computador do atendente todo o histórico de operações que o cliente fez com a empresa. E, se o funcionário que está se comunicando com o cliente não houver sido treinado adequadamente para esse fim ou não tiver habilidade para se comunicar de maneira criativa, todo esse investimento em tecnologia e processos não trará nenhum benefício. O importante é o contato com o cliente, que não é determinado pela tecnologia e pelos processos, mas pela comunicação.

A empresa pode adquirir uma vantagem competitiva, quando consegue aumento da retenção e da lealdade do cliente. Os clientes ficam com a empresa por períodos mais longos, compram mais e também o fazem com maior frequência Haverá maior lucratividade por cliente, e não apenas porque cada cliente compra mais, mas em função de: custos menores para seduzir os clientes, de um volume de negócios mais estável e da redução do custo de venda, haja vista que os clientes já existentes reagem mais prontamente aos apelos de marketing.

A criação de valor para os clientes, e a fidelidade, mede de forma confiável se a empresa gera valor: os clientes continuam comprando dela ou preferem outra empresa. A fidelidade aumenta as receitas e a participação no mercado, e o crescimento sustentável permite atrair e conservar os melhores funcionários, e os investidores fiéis viram sócios.

É preciso considerar a fidelidade como uma estratégia, não uma tática. $\mathrm{O}$ objetivo de um negócio é criar valor, não apenas produtos, que no caso do turismo é a criação de roteiros e programação especial para um grupo de clientes com perfil e comportamento já conhecidos. A fidelidade proporciona um padrão para medir o desempenho e um ponto de referência para alcançá-lo. 
Kotler (2000) ressalta que as empresas baseadas na fidelidade devem lembrar-se de três regras básicas: alguns clientes são intrinsecamente previsíveis e fiéis; alguns são mais rentáveis que os outros; e, por último, alguns acharão que os produtos e serviços da empresa são mais valiosos que os de seus concorrentes. $\mathrm{O}$ autor mostra que nem sempre satisfação é sinônimo de fidelidade. Fidelidade significa que estamos dispostos a sacrificar, pelo menos por um tempo, nossos interesses. Medir a satisfação é útil, mas não se deve transformar isso na ferramenta central. Como se mede a fidelidade? Observando quantos clientes voltam a comprar e quantos compram mais, ano após ano.

Dessa maneira, pode-se observar que o turismo "single" é uma segmentação de mercado do turismo que abrange várias interfaces. Os praticantes do turismo denominado "single" têm uma série de preferências que tenderá, em algumas circunstâncias, a outros segmentos. Esse mercado não se baseia somente no turismo, mas também no cotidiano da sociedade atual, desde projetos imobiliários, a produtos alimentícios, buscando a individualização e a personalização dos serviços e produtos oferecidos às características percebidas dos grupos que compõem o segmento.

\section{PROCEDIMENTOS METODOLÓGICOS}

A pesquisa realizada teve o objetivo de descrever se as estratégias competitivas dos agentes econômicos que incluíram no seu portfólio de negócios um programa específico para o turismo "single" conseguiram a lealdade e fidelidade desse grupo de clientes e obtiveram vantagem competitiva sobre os concorrentes que não adotaram esse tipo de segmentação.

A pesquisa exploratória-descritiva pode assumir diversas formas, sendo uma delas o estudo de caso, que é o objeto desse estudo. Em paralelo, foi feito o uso da observação passiva realizada durante a aplicação das entrevistas, de forma que os elementos observados pudessem confirmar ou desencadear novas perguntas abertas para as entrevistas.

Como tipologia de posicionamento estratégico, adotou-se o modelo de Porter (1991): Estratégia de Diferenciação, Estratégia de Custo e Estratégia de Foco. Após a aplicação de diversos filtros para reconhecermos uma estratégia específica, foram selecionadas quatro empresas que serão denominadas Agência A, Agência B, Agência C, e Agência D.

O que justifica essa relação de empresas escolhidas para a realização desta pesquisa é que as mesmas desenvolveram atividades voltadas ou envolvendo especificamente esse público. Segmentaram o turismo no setor "single", aproveitando uma nova fatia de mercado.

A Agência A é a mais agressiva na operação de turismo com o mercado "single". A empresa procura se comunicar com esse público de forma direta e clara mediante o apelo "just for singles". Acompanha essa promoção o anuncio de ser possuidora do primeiro e único clube voltado inteiramente ao perfil de "single" e que foi criado com a finalidade de promover o bom relacionamento, a integração e a convivência harmoniosa entre seus associados. O Singles Club visa a promoção de eventos que atendam seus interesses, anseios e necessidades na área de lazer, cultura e entretenimento, tais como viagens, festas, cursos, workshops, esportes, etc., no estado, no país e no exterior. Como todas as empresas do setor, oferece pacotes especiais para o segmento em ocasiões e datas especiais e principalmente em feriados prolongados.

A Agência B é uma organização que tem uma modalidade diferenciada e muito procurada por estudantes que precisam se associar à Instituição. A APAJTUR - APAJ Viagens e Turismo Ltda., agência de turismo da Associação Paulista de Albergues da Juventude, ajuda os associados da APAJ a organizar a viagem para o Brasil ou exterior. Passagens aéreas nacionais e internacionais, passagens com tarifas para estudantes, passes de trem europeu, seguro viagem, cursos no exterior, etc. Opera na cidade de São Paulo desde 1992.

A Agência C destina o turismo "single" para clientes de poder aquisitivo alto. O luxo é o apelo principal da empresa em todas as operações de turismo que realiza. Oferece viagens exclusivas, exóticas, o que traz uma imagem diferenciada para a empresa. Procura a fidelização do cliente através da utilização de mala direta e envio de catálogo, atualizado a cada três meses, mostrando os novos "pacotes" e roteiros diferenciados. Conta, ainda, com pessoas especializadas em formação de roteiros para cada segmento explorado.

A Agência D identificou através da procura pelos seus serviços a existência do mercado "single" e a partir desse reconhecimento passou a desenvolver "pacotes" especiais para esse segmento. Dessa forma, aproveita uma nova oportunidade de mercado e procura a fidelização atendendo as necessidades dos clientes. Está classificada como uma das maiores operadoras do Brasil em cruzeiros marítimos.

Para atingir os objetivos propostos, foi utilizado um roteiro de perguntas abertas e fechadas, que foi aplicado às pessoas com cargos de gerência, de relações públicas, marketing e de direção nessas empresas. $\mathrm{O}$ questionamento aos entrevistados abordou os seguintes assuntos, além da caracterização da empresa e do entrevistado.

- política de segmentação de mercado

- vantagem competitiva decorrente

- participação de mercado, rentabilidade

- fidelização e satisfação do cliente

- $\quad$ estratégia de operação

- caracterização do mercado "single" 
- estratégia para conquistar o mercado "single"

- dificuldades e limitações das operações no mercado "single"

\section{RESULTADOS DA PESQUISA}

$\mathrm{Na}$ percepção dos entrevistados as estratégias de segmentação de mercado do turismo
Das quatro empresas que exploram o segmento "single", a Agência A é a única que concentra todos os seus esforços nesse mercado, ou seja, a empresa adota uma estratégia de concentração de mercado.

Quadro 1. Segmentação e os fatores competitivos do mercado

1. A segmentação do mercado do turismo ao decompor a população em grupos de igual gênero e natureza possibilita um maior grau de fidelização dos clientes.

2. A segmentação do mercado do turismo propicia um programa de marketing próprio e focalizado nas características do segmento.

3. A segmentação do mercado do turismo favorece a adequação dos "pacotes turísticos" em termos de destinos geográficos potenciais, do tipo de transporte, da acomodação, dos passeios, visitas e locais atrativos para esse público.

Fonte: autores

Os fatores acima descritos confirmam o posicionamento dos teóricos do marketing de que a segmentação do mercado permite a empresa satisfazer preferências, necessidades e desejos específicos de seus consumidores de forma mais eficaz (SMITH, 1956; MCCARTHY, 1982; LAGE 1992; KOTLER, 1992; LAGE E MILONE, 2001).

Em relação à concorrência, na percepção dos gestores entrevistados, no mercado do turismo o conhecimento do setor e a busca por uma posição favorável em relação às forças competitivas se tornam extremamente importantes para verificar como as forças que atuam nesse mercado são fatores determinantes para o crescimento ou mesmo de sobrevivência da empresa.

Assim, todos os entrevistados foram unânimes em afirmar que a segmentação aumenta o share da empresa, propiciando confiança aos gestores e aos clientes, embora não entendam como uma vantagem competitiva, exceto a Agência $A$ que trabalha somente com esse segmento. Efetivamente a especialização é uma grande vantagem competitiva, segundo a gerente de marketing entrevistada. Concordam também que quando demonstram maior confiabilidade e especialização nos serviços prestados, podem conseguir mais facilmente a atração de novos clientes, tanto para turismo nacional como internacional.

A política de segmentação adotada não provocou mudanças expressivas na estrutura e no comportamento da organização, pois houve tão somente uma adequação de um produto que essas empresas já comercializavam há alguns anos. Em outras palavras, passaram a atender um nicho de mercado, que não podiam simplesmente desconsiderar, para não perder uma fatia de mercado.

Todas as empresas pesquisadas são estruturadas de forma funcional, onde as pessoas engajadas numa determinada atividade são agrupadas numa mesma unidade, como marketing, atendimento a clientes, formação de novos pacotes/roteiros, etc. O atendimento específico ao segmento "single" fica diluído nessa estrutura funcional, mas ao se elaborar um roteiro exclusivo para o segmento, todos os setores são informados sobre todas as especificações do "pacote" e orientados para o atendimento mais personalizado desse grupo de clientes.

Os entrevistados foram unânimes em afirmar que existe uma grande demanda potencial para o turismo "single", mas existe também uma grande dificuldade em atingir este público. Alegam que não existem meios de comunicação especificamente dirigidos para esse público e os meios de comunicação ampla são muito caros. A manutenção e ampliação de um cadastro através da promoção "boca a boca", é considerada pela gerente da Agência A o meio mais eficaz e ao qual a empresa dedica muita atenção.

Outro grande problema é o preconceito que ainda existe de se confundir turismo para sós com turismo sexual. As empresas apontam a dificuldade de encontrar pessoas dedicadas, preparadas e disponíveis para trabalhar com situações delicadas, às vezes até constrangedora, que ocorrem no processo desde o contato inicial com o potencial cliente.

Apesar de haver um mercado promissor, a tendência do mercado é personalizar cada vez mais a oferta, embora não existam à disposição de todos interessados as pesquisas de mercado que identifiquem melhor o comportamento (hábitos, costumes, atitudes, preferências de leitura, etc.) da pessoa só. A contratação de um trabalho desse tipo por uma única empresa, embora seja considerado essencial por teóricos, como Oliveira, Campomar e Luis (2008), para os entrevistados tal procedimento 
nem sempre se torna pertinente, visto que, representa custo muito elevado e retorno incerto.

\section{O ambiente competitivo das empresas de turismo}

O conhecimento do setor que a empresa turística está inserida é condição indispensável para o processo de elaboração e implementação das estratégias, que deverão estar condizentes com a estrutura do setor. No mercado do turismo a competição não se manifesta somente pelos concorrentes, mas também pelo grau ou estado de concorrência do setor, como na perspectiva das cinco forças competitivas (PORTER, 1991): ameaça de entrada de novos concorrentes, poder de negociação dos fornecedores, poder de negociação dos compradores, ameaça de produtos substitutos e rivalidade entre os concorrentes existentes.

A análise cuidadosa dessas cinco forças remete ao conceito de que tais forças não possuem o mesmo grau de relevância na forma de concorrência nos diferentes setores. Dessa forma, todas determinam a intensidade da concorrência, sendo que as forças mais intensas determinam a lucratividade do setor (PORTER, 1991), por isso, é importante que as empresas conheçam as fontes básicas de cada uma das forças, facilitando o reconhecimento dos pontos fortes e fracos da empresa no setor. Essa análise evidencia as mudanças estratégicas que possam oferecer melhores vantagens e acentua as situações em que as tendências do setor possam ser mais relevantes.

As organizações podem adotar estratégias que estão relacionadas a produtos e mercados. A adoção de tais estratégias fornece uma orientação para a empresa no que diz respeito aos produtos e aos mercados e resultam que os componentes desse vetor estão relacionados às estratégias de penetração de mercado e desenvolvimento de mercados. A primeira, propõe uma direção de crescimento por meio do aumento da participação relativa da empresa nas suas linhas correntes de produtos e mercados; a segunda, a empresa busca novos mercados para seus produtos atuais, como propostos nas estratégicas genéricas de Porter (1991), conforme quadro 2.

Quadro 2. Estratégias genéricas

\begin{tabular}{|l|l|}
\hline Estratégias & Posicionamento Estratégico \\
\hline Baixo Custo & $\begin{array}{l}\text { Busca-se alcançar a liderança total em custo por meio de políticas funcionais, o que } \\
\text { permite à empresa alcançar retornos acima da média na disputa com a concorrência, } \\
\text { propiciando flexibilidade para negociar com os fornecedores e, ao mesmo tempo, gerar } \\
\text { barreiras de entrada ao se colocar em posição privilegiada em relação aos produtos } \\
\text { substitutos. }\end{array}$ \\
\hline Diferenciação & $\begin{array}{l}\text { A empresa pode se diferenciar por meio da marca, da imagem, da tecnologia, da rede de } \\
\text { fornecedores, etc.. Dessa forma, pode alcançar posição diferenciada diante da concorrência } \\
\text { para ser depositária da lealdade dos consumidores. }\end{array}$ \\
\hline $\begin{array}{l}\text { Foco (em custo } \\
\text { ou diferenciação) }\end{array}$ & $\begin{array}{l}\text { A empresa se volta para um determinado grupo de compradores, um segmento da linha de } \\
\text { produtos ou serviços ou mesmo, um mercado geográfico ao abordar um ou mais segmentos } \\
\text { de mercado menores, ao invés de buscar competir no grande mercado. Assim, a } \\
\text { diferenciação pode ser alcançada ao satisfazer melhor as necessidades de um grupo de } \\
\text { clientes, ou custos baixos na obtenção desse alvo, ou ambos. }\end{array}$ \\
\hline
\end{tabular}

Fonte: elaborado pelos autores com base em Porter (1991).

Portanto, a segmentação de mercado para o perfil do turista "single" propicia a empresa foco em custo e diferenciação o que facilita a comunicação criativa como primeiro passo para se efetivar a passagem da atração pelo produto da empresa e pelo seu diferencial para a atração pela relação com o segmento (ZACARELLI, 2000).

\section{Construindo o perfil do turista "single".}

De acordo com os dados fornecidos pelos entrevistados, pudemos constatar a existência de várias categorias de "singles": viúvo, separado (divorciado ou desquitado), solteiro que fez a opção por morar sozinho ou solteiro que mora com outras pessoas, mas sente-se só, casados e/ou casadas solitárias em família, homossexuais que não encontraram seus pares e, ainda, os aposentados.
Essas diferentes pessoas têm em comum o fato de estarem sós numa cidade grande como São Paulo.

A tendência de redução de relações formais é detectada simultaneamente ao crescimento dos lares com apenas um morador, fato que também já havia sido constatado nos últimos anos nos Estados Unidos e na Europa. Segundo a Pesquisa Nacional de Amostra por Domicílios de 2011 do IBGE (2011), 800.000 pessoas passaram a viver sozinhas em uma residência desde o levantamento anterior realizado em 2009. Este percentual representa 7,8 milhões de moradores individuais no Brasil, entre solteiros (as), separados (as), homossexuais e pessoas que têm optado por não casar ou casar mais tarde.

O Censo Demográfico 2013 divulgado pelo IBGE (2013) aponta ainda que houve um aumento significativo no número de divórcios no Brasil. Segundo o IBGE, o percentual de divorciados quase 
dobrou, passando de $1,7 \%$, em 2000, para 3,1\%, em 2010. De 2012 para 2013, mais 370 mil pessoas deixaram de viver com o cônjuge, e o total de divorciados, desquitados e separados judicialmente chegou a 9,6 milhões. O estudo mostra também, que o aumento nos divórcios ocorreu especialmente a partir de 2007, ano em que eles puderam ser requeridos nos Tabelionatos de Notas, desde que houvesse consenso e o casal não tivesse filhos. São esses fatores que ocasionam o aumento do grupo de “ "singles” em São Paulo, fenômeno que também está ocorrendo em outras grandes cidades do país.

Baseado no cadastro de clientes das empresas entrevistadas, pudemos elaborar um perfil resumido do cliente típico desse segmento:

Gênero: predominância do gênero feminino na proporção de 10 mulheres para 8 homens.

Faixa etária: acima de 35 anos; excluindo a Agência $\mathrm{B}$, em razão da característica peculiar do seu público, composto por estudantes pré ou universitários. No segmento característico de "single", a predominância da faixa etária acima de 35 anos, se deve a alguns fatores:

- nessa faixa etária, quem não casou, perdeu de vista ou se encontra pouco com os amigos que estão casados;

- nessa idade já se tem um amadurecimento profissional, o que significa muito trabalho e pouco tempo para reuniões sociais;

- as férias podem não coincidir com a de seus amigos, e

- também está concentrada, nessa faixa etária e acima, o maior número de separações conjugais, assim como a viuvez.

Estado civil: os solteiros, viúvos, divorciados ou separados são os que mais aderem a esse tipo de programa, embora apareçam alguns casos eventuais de pessoas casadas. Não existe muita diferença entre as razões dadas por essas três categorias. Todos estão sós, e, portanto, é natural que busquem companhia. Os casados que viajam sós têm como um dos motivos à impossibilidade, por razões profissionais, de viajarem juntos. Outros motivos são os interesses divergentes de atividades durante as viagens e ainda aqueles que foram formados no grupo dos "singles" e que querem dar continuidade à amizade adquirida.

Profissão dominante: observam-se muitos profissionais liberais nos grupos e muitos aposentados. As agências consultadas não elaboram estatísticas sobre o perfil dos clientes, mas uma amostra das fichas cadastrais de clientes de cada uma mostrou que $100 \%$ das pessoas cadastradas nesse segmento possuem formação educacional superior.

Motivação de compra e ajustamento do produto.

$\mathrm{O}$ que tem levado os "singles" a procurar programas específicos, segundo o que foi levantado nas entrevistas, é a falta de companhia para viagens e a falta de amigos disponíveis. Mais especificamente os motivos apontados compreendem:

- a ausência de uma companheiro (a) para viajar na mesma época que a pessoa, mesmo tendo amigos ou familiares que viajam;

- a ausência de companheira(o) para viajar por estar isolado socialmente, por ter se aposentado, enviuvado, ou ainda por não ter cônjuge ou parentes próximos;

- a busca de uma maneira mais barata de viajar, pois não quer ou não pode pagar o custo da viagem individual, desejando compartir;

- a vontade de conhecer novas pessoas que, como ela, também estão sós, já que a viagem é vista como uma forma agradável de fazer novos amigos;

- o desejo de encontrar uma companheiro (a) para namorar ou passar horas agradáveis ou mesmo casa, e

- a tranquilidade de ter alguém organizando sua viagem.

Alguns desses motivos, apontados nas respostas dos entrevistados, se encontram na classificação estabelecida por Bacal (1984, p. 45), segundo a qual, os motivos predominantes no caso de turistas, seriam a expectativa de relacionamentos primários (companhia) durante a viagem e de deficiência, fugir dos relacionamentos instrumentais e do "vazio" das metrópoles.

Efetivamente, quaisquer que sejam os motivos apontados nesta pesquisa ou pelo estudo de Bacal (1984), todos eles têm em comum o desejo de contato humano, a busca de relações sociais. Mesmo os que viajam com outros "singles" para dividir, por razões econômicas, um quarto de hotel ou uma cabina de navio, desejam também manter um relacionamento com outra pessoa que, embora não sendo íntima, irá compartilhar do mesmo espaço e da convivência durante a viagem.

\section{A comunicação com o mercado}

As empresas do setor reconhecem que existe uma demanda potencial ainda maior para esse segmento. Entretanto, atingir a demanda potencial é uma tarefa difícil, uma vez que faltam canais de fácil acesso a esse público. Não há no mercado uma revista ou jornal especializado para "singles" como há para o público homossexual, que possuem até livraria temática. Há os bares para "singles", mas aquele que se sente muito só e tem vergonha ou medo de sair sozinho não frequentará esses bares. Não há centro de convivência ou cursos especiais destinados ao público "single" como existem para as pessoas da terceira idade. As agências matrimoniais indicam nos seus programas de encontros as agências de viagens 
que têm programas para "singles", mas muitos não procuram essas agências porque querem companhia e não casamento.

Existem várias maneiras de se promover um produto turístico, e a mais eficaz tem sido a comunicação boca-a-boca. $O$ que se percebe no turismo "single" é o uso frequente dessa forma de comunicação. Os primeiros grupos "singles" foram formados por pessoas conhecidas que os organizaram e procuraram a agência. Esses primeiros convidados acabaram levando outros, e assim os grupos se formaram.

A mala direta para clientes ou para pessoas indicadas tem sido um mecanismo usado por algumas empresas. O problema está em como fazer esse mailing. Além das pessoas conhecidas ou das que procuram a agência, como achar o solitário? Não é possível encontrá-lo em lista telefônica, nem em lista com relação de profissionais. Uma possibilidade de montar um mailing seria obter a relação de pessoas que frequentam bares para "singles", clubes para terceira idade, pessoas que procuram empresas casamenteiras, entre outros. Porém, aqueles que não saem de casa não serão encontrados. A aquisição de um cadastro de pessoas com essas características para ser utilizado via Internet, é uma alternativa viável, porém caro e pouco confiável, segundo os entrevistados.

Restaria, então, a comunicação de massa. Esta, porém, possui dois inconvenientes: em primeiro lugar, o de estar enviando uma mensagem para todos indiscriminadamente podendo ou não atingir alguém que queira companhia para viajar. Assim se estaria aplicando a difusão e não a segmentação. Quando se segmenta, uma das vantagens e uma das táticas é buscar o público específico gastando menos recursos humanos e financeiros. Segundo, para que os turistas tenham uma boa convivência durante a viagem, devem possuir afinidades o que não pode existir quando se tem um público genérico, frustrando a finalidade da viagem "single": a busca de relacionamentos sociais em viagens com seus pares. $\mathrm{O}$ segundo inconveniente se refere ao custo elevado dessa mídia.

A grande empresa geralmente possui uma assessoria de imprensa que a coloca em evidência, mas isso tem custo elevado. Ela também anuncia e é comum no Brasil, quando se fazem anúncios, conseguir um espaço para divulgar o produto em forma de nota ou de entrevistas, o que tecnicamente denominamos "publicidade". A pequena empresa já não tem recursos suficientes para fazer esses altos investimentos e, portanto, somente sai na grande imprensa se for "notícia".

$\mathrm{O}$ aumento da segmentação do turismo "single" depende de que a mensagem chegue ao consumidor. O grau de acessibilidade do segmento de viagens para "singles", como vimos, não é tão fácil, dificultando o recebimento da mensagem pelo receptor pretendido.
A forma ainda mais seletiva e eficaz acaba sendo as reuniões dos clubes de amizades, porque, além de criarem um vínculo com o grupo, também garantem a possibilidade de se realizar a póstransação e manter a fidelidade do cliente. Porém, manter esses clubes funcionando acarreta muito trabalho e exige que as empresas tenham um departamento ou uma pessoa especializada em trabalhar com grupos. Para empresas com grande movimento financeiro e muitas opções de segmentações, as viagens para "singles" podem não ser tão atrativas.

\section{CONSIDERAÇÕES FINAIS}

O objetivo da pesquisa foi o de investigar a segmentação de mercado como vantagem competitiva nas empresas que operam com programas ou "pacotes" de viagens especiais para o grupo de clientes denominado "single". A única empresa que reconhece a existência dessa vantagem é a Agência A que, como vimos, concentra todos os seus esforços promocionais nesse segmento. É uma agência que se dedica exclusivamente ao turismo "single". As demais agências pesquisadas que elaboram "pacotes" de viagens e formam grupos dentro desse segmento, afirmam que estão aproveitando um nicho de mercado com necessidades e condições especiais para viagens e turismo.

Verificou-se na pesquisa realizada, corroborando as premissas da literatura sobre o assunto, que a necessidade desse tipo de segmentação para as agências de turismo, pode ser atribuída à situação do homem moderno que vive em uma metrópole como São Paulo e tem alguma dificuldade de desenvolver relacionamentos humanos. Assim, a viagem para uma pessoa só traz um acréscimo de capital social às pessoas que participam do programa. Todos os entrevistados afirmam que muitas amizades surgiram nesses programas de viagens e muitos participantes estão juntos em diferentes pacotes para o segmento, há mais de cinco anos. Os encontros antes e pós-viagens, promovidos pelas agências, auxiliam a manutenção das relações sociais entre os viajantes, ao mesmo tempo em que permitem adiantar a programação de novos eventos e viagens.

Nas empresas visitadas na sondagem inicial, parte das pessoas que trabalhavam com esse tipo de turismo haviam se desligado da agência $e$, consequentemente, o programa foi encerrado. O deslocamento desses profissionais para outras agências propiciou que um "pacote" para esse segmento fosse adicionado ao portfólio de viagens dessas agências, evitando assim, a descontinuidade da oferta e garantindo esse tipo de turismo existente há mais de doze anos.

As empresas que optaram por segmentar seu mercado para o turismo "single" geralmente o fizeram por perceber a existência de um nicho latente a ser explorado. Há muitos “singles” em São Paulo, 
que pelos motivos anteriormente apontados aspiram a viajar com uma companhia adequada e que ofereça um programa especial. Pode-se constatar que há um grande potencial para esse segmento de mercado, mas que esbarra num problema de comunicação eficaz e de vontade política das empresas. Apesar de haver um mercado promissor, na medida em que existem vários tipos de "singles", é preciso, além de um bom produto, personalizar a oferta.

Entretanto, não existem informações classificadas para se conhecer melhor o turista "single". As empresas do setor e que exploram esse segmento, se utilizam do feeling pessoal de cada agente, observando e registrando o comportamento de seus clientes, de modo a obter dados agregados e um histórico do relacionamento do cliente com a empresa. Para os gestores dessas empresas, o perfil, a motivação, os desejos e as necessidades dos potenciais clientes dos seus produtos, se baseiam na realidade do comportamento aparente dos seus clientes atuais e habituais.

Enfim, pode-se dizer que as estratégias adotadas pelas empresas de turismo analisadas estavam relacionadas à sua própria estrutura competitiva, visto que o setor, de uma forma geral, se analisados na perspectiva de Porter (1991), não

\section{REFERÊNCIAS}

ANGOTTI, A. R. (2002) Os novos complexos turísticos. Revista Viagem e Turismo. Editora Abril. São Paulo.

ANUARIO 2015 - BASE 2014. Disponível http://www.observatoriodoturismo.com.br/pdf/ANU ARIO_2015_BASE_2014.pdf. Acesso em 04/03/2016.

BENI, M. C. (1998) Análise estrutural do turismo. São Paulo. SENAC.

BACAL, S. S. (1984) Pressupostos do Comportamento Turístico: influências psicológicas, socioculturais $\boldsymbol{e}$ econômicas. Escola de Comunicações e Artes USP. Tese de Doutorado.

COOPER, C. et al. (2001). Turismo: princípios e prática. 2. ed. Porto Alegre: Bookman.

CORTÉS-JIMÉNEZ, I. (2008). Which type of tourism matters to the regional economic growth? The cases of Spain and Italy. International Journal of Tourism Research, 10 (2), 127-139.

DEDE, A. (2013). An Exploration of the Motivating Cultural Experience Factors That Determine a Holiday Destinations' Selection and possui barreiras de entrada para novas empresas, portanto, a possibilidade de novos entrantes ameaça continuamente a competitividade das empresas. Outro ponto que deve ser destacado é a intensa rivalidade entre os concorrentes existentes, tanto na alta, como na baixa temporada, o que justifica a adoção da segmentação, como forma de sobrevivência no próprio mercado.

A contribuição da pesquisa está em proporcionar subsídios para se entender as especificidades das teorias relacionadas à segmentação do mercado "single" no turismo com as estratégias de diferenciação e de custos propostas no posicionamento porteriano.

Evidentemente, essa pesquisa possui limitações, tanto pela representatividade da amostra tamanho da amostra quanto pela forma de registro dos agentes em relação ao comportamento dos clientes. A continuidade da pesquisa descrita neste artigo seria ampliar o universo de pesquisa, de forma a obter uma amostra representativa que permitisse uma análise quantitativa da relação entre estratégia competitiva e desempenho empresarial, fornecendo subsídios para a verificação da validade desse controverso construto nas agências de turismo.

Respective Competitiveness. SAGE Open, 3 (4), $67-$ 89.

ELLIOT, S., \& CHOI, H. S. (2011). Motivational Considerations of the New Generations of Cruising. Journal of Hospitality and Tourism Management, 18 (01), 41-47.

FERREIRA, A. B. H. (1986) Novo Dicionário Aurélio da Língua Portuguesa. Editora Nova Fronteira. Rio de Janeiro

HAMEL, G., PRAHALAD, C. K. (1995). Competindo pelo futuro: estratégias inovadoras para obter o controle do seu setor e criar mercados para o amanhã. Rio de Janeiro. Campus.

HARRIS, L. C.; WATKINS, P. 1998. The impediments to developing a market orientation: an exploratory study of small UK hotels. International Journal of Contemporary Hospitality Management. v. 10 , n. 6 , p. 221-226.

HOELLER, E. H. (2002) Turismo de incentivos. In ANSARAH, M. G. R. (Org.). Turismo segmentação de mercado. São Paulo. Futura.

HU, C. 1996. Diverse developments in travel and tourism marketing: a thematic approach. International 
Journal of Contemporary Hospitality Management, v. 8, n. 7, p. 33-43.

IBGE (2010). Censo Demográfico Características da População e dos Domicílios. Instituto Brasileiro de Geografia e Estatística. Rio de Janeiro.

IBGE (2011) Pesquisa Nacional de Amostra por Domicílios. Instituto Brasileiro de Geografia e Estatística. Rio de Janeiro.

IGNARRA, L. R. (2001) Fundamentos do turismo. São Paulo. Pioneira.

KOTLER, P.(2000) Administração de Marketing 10 ed. A edição do novo milênio. São Paulo. Prentice Hall.

LAGE, B. H. G. (1992) Segmentação do mercado turístico. Turismo em análise, v. $3, \mathrm{n}^{\circ} 2$, nov. ECA/USP. São Paulo.

LAGE, B. H. G.; MILONE, P. C. (2001) Economia do turismo. São Paulo. Atlas.

McCARTHY, E. J. (1982) Marketing. Rio de Janeiro. Campus.

MTUR (2012a). Turismo já representa 3,7\% do PIB. Ministério do Turismo, Brasília. Disponível em http://www.turismo.gov.br/turismo/noticias/todas_not icias/20121010-2.html. Acesso em 15/01/2016

MTUR (2012b) Financiamentos para o Turismo crescem 38\% em 2012. Ministério do Turismo. Brasília. Disponível em http://www.dadosefatos.turismo.gov.br/dadosefatos/g eral_interna/noticias/detalhe/20120723.html. Acesso em $15 / 01 / 2016$

MORAES, C. C. A. (2002) Turismo para single: uma segmentação em crescimento. In ANSARAH, M. G. R. (org.). Turismo - Segmentação de mercado. São Paulo. Futura

OLIVEIRA, B; CAMPOMAR, M. C; LUIS, Carolina. 2008. Posicionamento estratégico em turismo: o caso Sabre Brasil. Turismo em Análise, v. 19, n. 1, p. 64-84, maio 2008.

OMT (1978) Organização Mundial de Turismo. $\boldsymbol{A}$ imagem turística, estudo elaborado como atrativo especial de programa: promoção e comércio turístico.

OMT (2003) Organização Mundial do Turismo. Turismo Internacional: uma perspectiva global. 2 ed. Porto Alegre. Bookmann.
OMT (2014) Organização Mundial do Turismo. Disponível em http://www.observatoriodoturismo.com.br/pdf/ANU ARIO_2015_BASE_2014.pdf. Acesso em 04/03/2016.

PORTER, M. E. (1999) Competição (on competition): estratégias competitivas essenciais. Rio de Janeiro: Campus.

(1991) Estratégia competitiva: técnicas para análise de indústrias e da concorrência. 7. ed. Rio de Janeiro: Campus.

(1990) Vantagem competitiva: criando e sustentando um desempenho superior. Rio de Janeiro. Campus.

SMITH, W. R. (1956) Product differentiation and marketing segmentation as alternative marketing strategies. American Marketing Association. Journal of Marketing, vol. 21, pp. 3-8, julho.

STOKES, R. (2008) Tourism strategy making: insights to the events tourism domain. 2008. Tourism Management, v. 29, n. 2, p. 252-262.

ZACCARELLI, S. B. (2000) Estratégia e sucesso nas empresas. São Paulo. Saraiva. 